\title{
Endoscopic removal of impacted Dormia basket: The post- cut procedure
}

\author{
Wael Ferjaoui*, Mohamed A Chaouech, Wafa B Hmida, Riadh Bouali, Wafa Ghariani, Hichem Jerraya and Ramzi Nouira \\ Department of Surgery B23, Charles Nicolle Hospital, Tunisia
}

\begin{abstract}
Endoscopic procedures are widely used for the management of bile duct stones. Pancreatitis, haemorrhage, cholangitis and intestinal perforation are the most commonly reported complications. Impaction of stone-retrieving devices such as Dormia basket is rare. It can be removed using a smaller basket, balloons, percutaneous transhepatic removal, laparoscopic retrieval or even through laparotomy. In our case, it was feasible and safe using the post cut technique which is a type of a second biliary sphincterotomy performed after a previous sphincterotomy in order to enlarge the papillary orifice and to extract the impacted Dormia basket.
\end{abstract}

\section{Introduction}

Endoscopic management is the first line therapy of common bile duct stones [1]. In most cases, they are successfully extracted with Endoscopic Retrograde Cholangiopancreatography (ERCP) and endoscopic sphincterotomy (ES) using a Dormia basket or balloon catheters [1]. This endoscopic treatment ensures less morbidity and mortality then surgery [1]. The most common complications of endoscopic treatment are pancreatitis, bleeding and perforation [2]. Recognizing other less common events like Dormia basket impaction is important in order to prevent disastrous outcomes. The aim of this article is to report a case of Dormia basket impaction that could be managed using an endoscopic technique called the post-cut procedure in order to prove its efficiency and safety.

\section{Case report}

A 78-year-old female with a past surgical history of laparoscopic cholecystectomy 17 years ago, presented with abdominal pain in the epigastric and right upper quadrant region associated with dyspepsia for 3 months. She did not present fever or jaundice. The abdominal exam was normal. Laboratory data revealed cholestasis and cytolysis with elevated serum total bilirubin to $19.3 \mu \mathrm{mol} / \mathrm{L}$, direct bilirubin was $6.87 \mu \mathrm{mol} / \mathrm{L}, \gamma$-glutamyl-transferase (GGT) was $198 \mathrm{U} / \mathrm{L}$, alanine transaminase (ALT) was $131 \mathrm{U} / \mathrm{L}$, aspartate transaminase (AST) was $154 \mathrm{U} / \mathrm{L}$. Abdominal ultra-sonography showed the increased diameter of the common bile duct to $22 \mathrm{~mm}$ with common bile duct (CBD) stones. She was treated with ERCP with the impossibility to extract all stones. Then she was planned for a second ERCP. Unfortunately, in this second opportunity, the Dormia basket advanced within the CBD has been impacted with a round entrapped stone and could not be disengaged. Mechanical lithotripsy was performed. The basket wires were broken and remained impacted inside the CBD (Figure 1).

The trial of common bile duct dilatation using biliary balloon was unsuccessful. The patient was referred to our department for surgical treatment. However, the decision was to try another time the endoscopic solution by another experienced endoscopist especially since the patient did not have any complications. During the third ERCP, a needle knife was introduced next to the basket catheter and wires (Figure $2 \mathrm{~A}$ and $2 \mathrm{~B}$ ). This needle-knife was gently inserted into the papillary orifice (Figure 2B). An extended incision was made superiorly toward the position over the basket wire along the long axis of the distal CBD (Figure 2C). A proximal piece of the basket was held endoscopically with the biopsy forceps. It was pulled to duodenum by first forward then backward traction of the biopsy forceps. The ERCP process was terminated with the insertion of a plastic biliary stent in the CBD (Figure 2D). The post-operative delay was uneventful, and the patient was discharged after 24 hours. The patient consulted after 3 months. She was asymptomatic. The abdominal exam was normal.

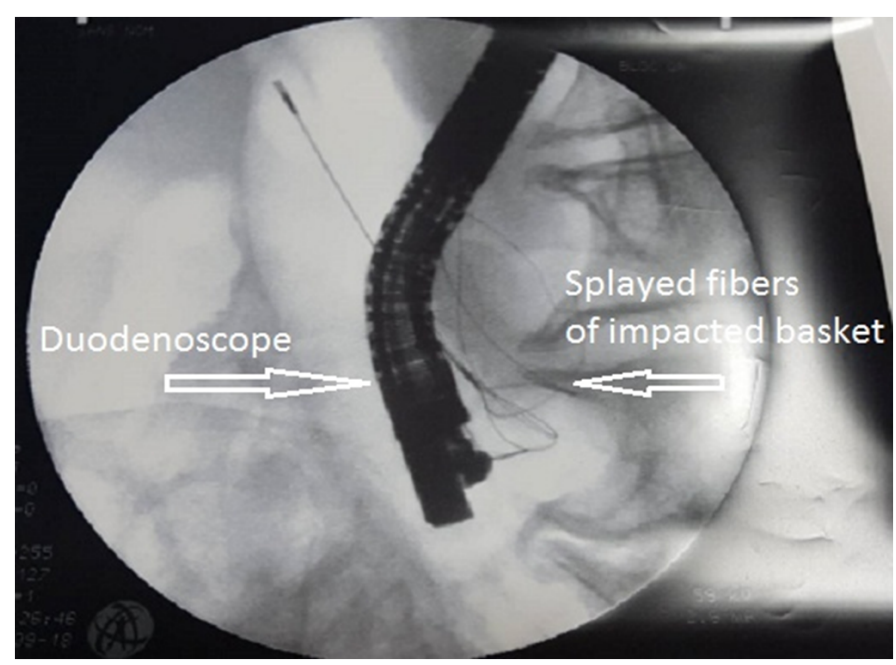

Figure 1. Splaying of impacted basket fibers.

${ }^{*}$ Correspondence to: Wael Ferjaoui, Department of Surgery B23, Charles Nicolle Hospital, Tunisia, Tel: +216 52430099; E-mail: farjaouiwael4@gmail.com

key words: common bile duct stone, impacted Dormia basket, post cut

Received: July 15, 2019; Accepted: August 01, 2019; Published: August 05, 2019 


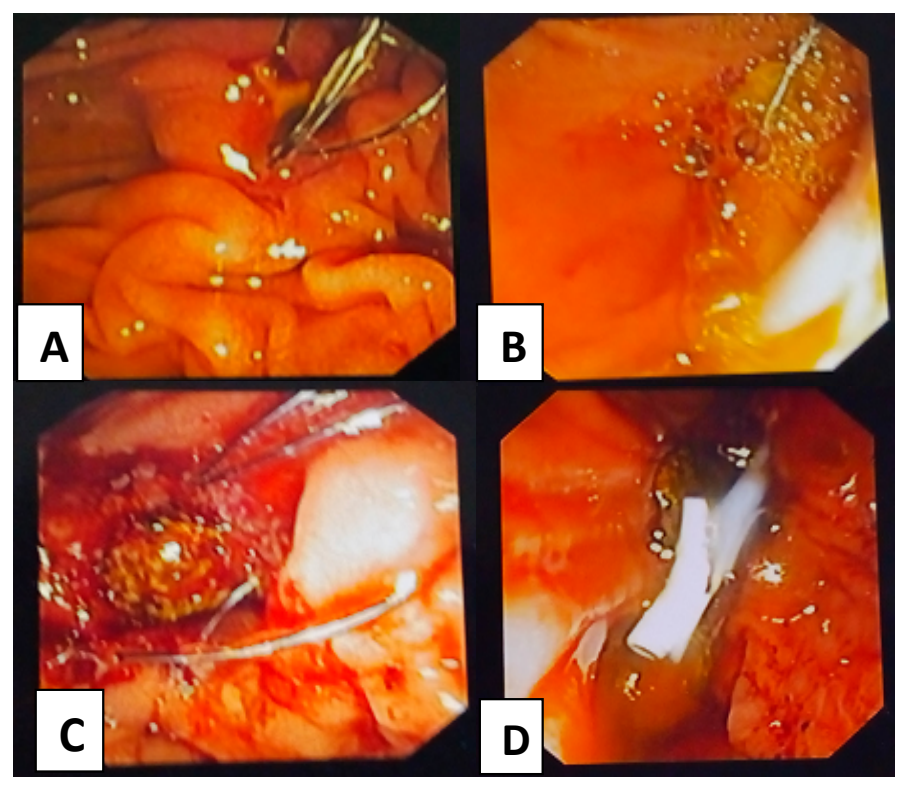

Figure 2. Endoscopic photos showing the post-cut technique. A) Impacted stone/Dormia within the ampulla, B) The needle-knife is inserted into the papillary orifice, C) Retrieval of the entrapped stone/Dormia, D) Insertion of a plastic biliary stent in the CBD

\section{Discussion and conclusion}

Choledocholithiasis present one of the most frequent indications of ERCP. ERCP is a non-invasive biliary and pancreatic treatment but it is not free of complications. Their usual complications include acute pancreatitis, haemorrhage, perforation and cholangitis [2]. However, other rare complications may occur like in our case: Dormia Basket impaction in the CBD. It presents 0.8 to $5.9 \%$ of ERCP complications [1-4]. In order to deal with this challenging unusual problem, several techniques have been proposed in the literature. Open and laparoscopic approach were reported in the literature $[5,6]$. Lithotripsy, extracorporeal shock wave lithotripsy, extra-endoscopic mechanical lithotripsy, transhepatic choledochoscopic lithotripsy, endoscopic pulse-dye laser are all techniques reported in the literature also. But, the rarity of this complication does not allow establishing a clear therapeutic strategy. In our case, this accident was treated successfully using an endoscopic approach: post cut procedure. A recent study carried out by Wei et al. [4] on 21 patients who presented impacted Dormia basket during ERCP. In 10 patients, Post-cut was carried out. It was successfully done in all patients. There were no complications with complete clearance of the biliary tree. It is a procedure which consists of enlarging a biliary sphincterotomy already done. It allows so to extract the impacted Dormia basket with stone. Biopsy forceps may be also used, as it was performed in our case. This study showed the efficiency and the safety of this method compared to other techniques. Indeed, in our case, 2 others endoscopic techniques were used with failure before the post cut. Some complications such as bleeding or perforation can occur. So, an experienced endoscopist required to perform this endoscopic treatment. Nevertheless, the post cut manoeuvre is to be considered as an effective and sure way to deal with impacted Dormia Basket before referring the patient for more invasive treatment including surgery with their potential complications.

\section{References}

1. Schreurs WH, Juttmann JR, Stuifbergen WNHM, Oostvogel HJM, Vroonhoven TJMV (2002) Management of common bile duct stones. Surg Endosc 16: 1068-1072. [Crossref]

2. Suissa A, Yassin K, Lavy A, Lachter J, Chermech I, et al. (2005) Outcome and early complications of ERCP:a prospective single center study. Hepato-gastroenterology 52 : 352-355. [Crossref]

3. Sauter G, Sackmann M, Holl J, Pauletzki J, Sauerbruch T, et al. (1995) Dormia Baskets Impacted in the Bile Duct: Release by ExtracorporealShock-WaveLithotripsy. Endoscopy 27: 384-347. [Crossref]

4. Liu W, Zhang LP, Xu M, Zeng HZ, Zeng QS, et al. (2018) "Post-cut": An endoscopic technique for managingimpactedbiliary stone within an entrapped extraction basket. Arab J Gastroenterol 19: 37-41. [Crossref]

5. Filiz AI, Sucullu I, Aydin Y, Kurt Y (2009) Biliary basket impaction-a rare complication of ERCP: report of a case. Gulhane Tip Dergisi 51: 254-255.

6. Sahoo MR, Kumar S, Ahammed PS (2017) Laparoscopicretrieval of impacted Dormia basket. J Minim Access Surg 13: 237. [Crossref]

Copyright: (C2019 Ferjaoui W. This is an open-access article distributed under the terms of the Creative Commons Attribution License, which permits unrestricted use, distribution, and reproduction in any medium, provided the original author and source are credited. 